Hazards in the workplace

\section{World at work: Hazards and controls in aluminium potrooms}

\section{Sim, G Benke}

\section{First of a new series}

$\mathrm{T}$ he primary aluminium industry is one of the largest industries in the world today. World production exceeded 20 million metric tons in 2001 (IAI, 2002) and production is widespread throughout the world. Aluminium as the pure metal or in alloys is used to make a range of products including aircraft, utensils, scientific and domestic apparatus, electrical conductors, and automotive parts. Aluminium powders are used in paints, explosives, and fireworks.

Aluminium is produced by the HallHeroult process, which involves the electrolytic reduction of alumina $\left(\mathrm{Al}_{2} \mathrm{O}_{3}\right)$ in large carbon lined steel vessels called pots. Hundreds of these pots are housed in a "potroom". Pots may be of two types of technology, either Søderberg or prebake, with prebake potrooms the preferred design in modern smelters because of lower levels of emissions. ${ }^{1}$ In a pot, alumina is partially dissolved in an electrolyte of molten cryolite $\left(\mathrm{Na}_{3} \mathrm{AlF}_{6}\right)$ at approximately $960^{\circ} \mathrm{C}$. It is a continuous process that requires large amounts of direct current electrical power to operate the pots (Giga-watt-hours per annum). The older Søderberg process bakes the anode paste in situ in the pot, whereas the prebake process uses baked anodes manufactured in a separate part of the smelter, usually called the anode factory or electrode plant.

\section{JOBS AND TASKS IN THE POTROOM}

In prebake and Søderberg potrooms there are many jobs and tasks, but the main ones common to most prebake potrooms are:

- Tapping and anode changing, which involves crust breaking, carbon anode changing, molten metal removal (tapping), transferring molten electrolyte, and covering of anodes with ore. In most modern pre-bake smelters the anode changing and tapping tasks are now usually undertaken from purpose built overhead cranes which house the operator in an airconditioned and filtered cabin. The crane has all attachments necessary to carry out the routine anode changing. In older plants the setting of the anodes is undertaken by crews of two or three setters working on two to four pots at a time. Tapping is generally done by vacuum siphoning liquid metal or bath into purpose built crucibles.

- Pot tending, which involves checking that the pots are running properly, checking alumina additions, temperatures, electrolyte levels, and anode effects (gas production that disrupts current flow).

- Pot-lining, that involves dismantling pot superstructures, digging spent pot-linings and refractory, then rebuilding the pot-lining before rebuilding the superstructure.

- Crane and vehicle driving, which involves driving the overhead travelling cranes for the crews doing the tapping and setting and vehicles that assist in the same and other miscellaneous operations.

- In addition to these tasks there are also mechanical and electrical tradesmen and fitters regularly undertaking maintenance on the feeders, and mechanical and electrical systems.

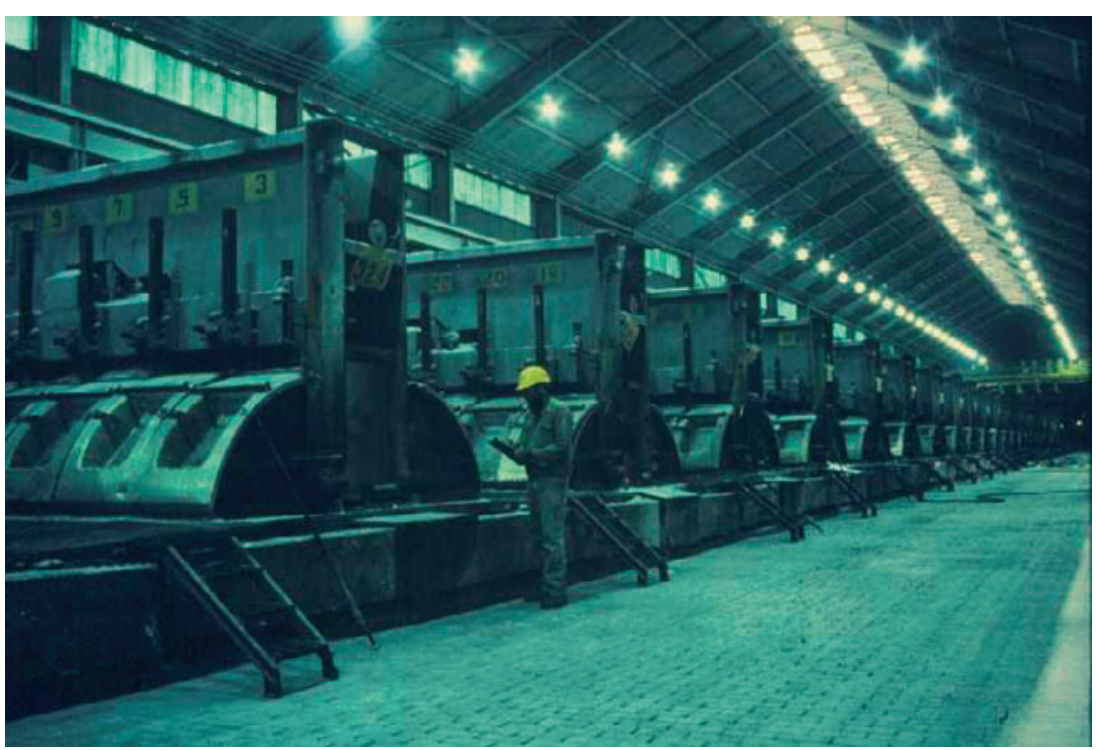

Figure 1 Typical pre-bake potroom. (PAHs) which sublime in the pot-
Crusher operators operate the bath (frozen electrolyte) crushing facilities as well as crucible auger cleaning facilities. Other important tasks in a prebake potroom involve process control, anode transport, and the transport of the metal out of the potroom in crucibles.

\section{HAZARDS IN ALUMINIUM POTROOMS}

The main hazards of jobs in potrooms are chemical, physical, ergonomic, and psychological in nature. Details of the hazards in aluminium potrooms have been described elsewhere ${ }^{12}$ and only an overview is given here. Some of the main hazards are listed in table 1.

Chemical hazards of main concern include:

- Coal tar pitch volatiles (CTPV) which are released continuously from baking anodes in the Søderberg process, and released from potlining seam mix during start-up of a pot in the pre-bake process. The volatiles contain many lower molecular weight polycyclic aromatic hydrocarbons room air. Reported exposures to PAHs are generally much lower in the pre-bake potrooms compared to the Søderberg potrooms. ${ }^{3}$ Reported exposures to TWA levels of benzo-apyrene in modern pre-bake potrooms rarely exceed $10 \mu \mathrm{g} / \mathrm{m}^{3} .{ }^{14}$

- Fluorides (both dusts and gas) from the electrolyte bath. In modern potrooms total fluoride exposure (includes dust and gas) are generally below the ACGIH-TLV time weighted average (TWA) of $2.5 \mathrm{mg} / \mathrm{m}^{3}$.

- Other dusts (alumina and calcined coke). 


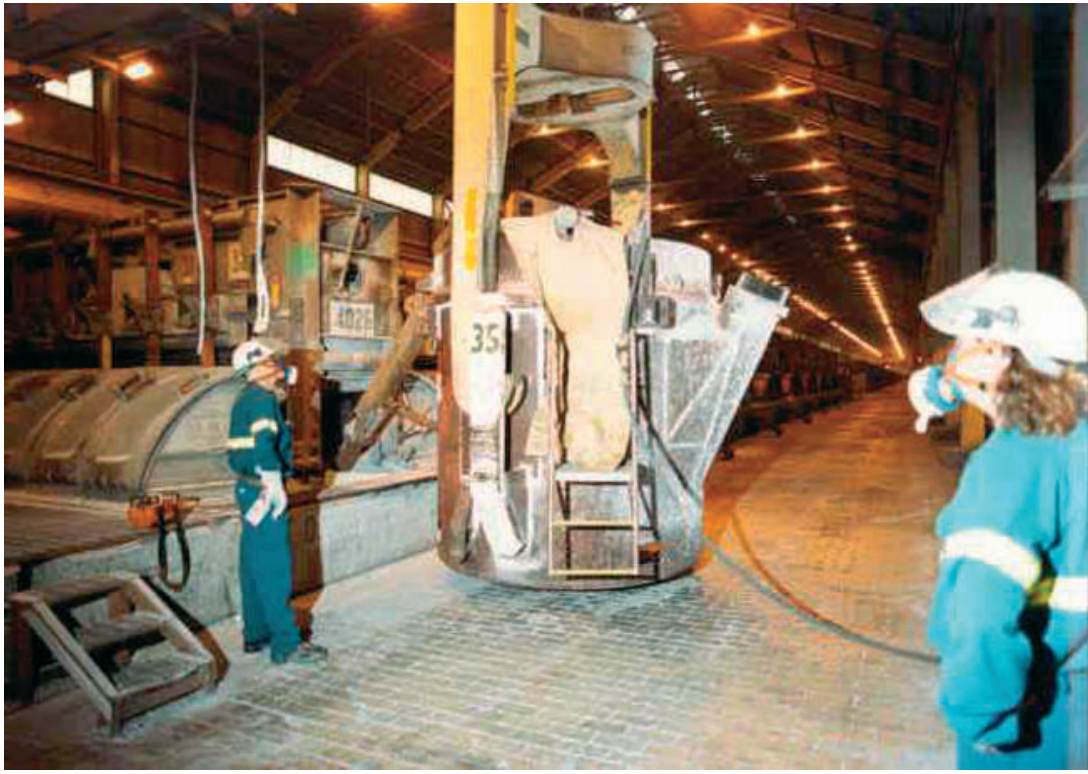

Figure 2 Potroom workers tapping metal in the pre-bake potroom.

- Other gases such as carbon monoxide and sulphur dioxide are also important chemical hazards.

Epidemiological studies ${ }^{56}$ have implicated these exposures as causal agents for excess cancers and/or respiratory disease in the primary aluminium industry. The atmospheric concentrations of the chemical contaminants vary in potrooms and are usually dependent on the technology used in the potroom and the age of the facility. ${ }^{3}$ Peak exposures to fluorides and sulphur dioxide may also be a hazard as extraction hoods must be removed from time to time, resulting in potential for significant levels of emissions over short time periods.
Typically, in many of the jobs and tasks the worker can be simultaneously exposed to all of these dusts and fumes. But it depends on the stage of the smelting process and task as to the "mix" of concentrations of the various exposures. The jobs and tasks with highest potential for exposure involve anode changing, metal and bath tapping, and pot-lining, although significant exposure to dusts and fumes can also be experienced by maintenance workers and crane drivers.

Potroom workers are also exposed to physical hazards such as magnetic fields, noise, radiant energy, and the likelihood of burns from hot metal. Since the pots in most potrooms operate at currents of $12-300 \mathrm{kA}$ at 5 volts,

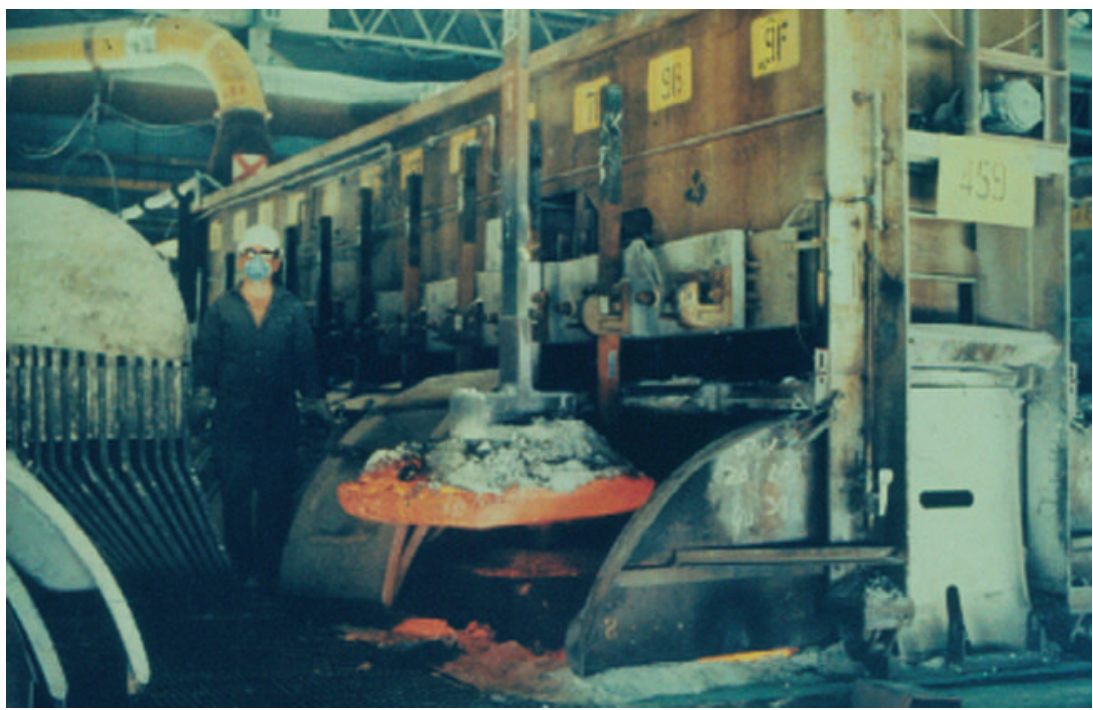

Figure 3 Removal of a spent anode in a pre-bake potroom.

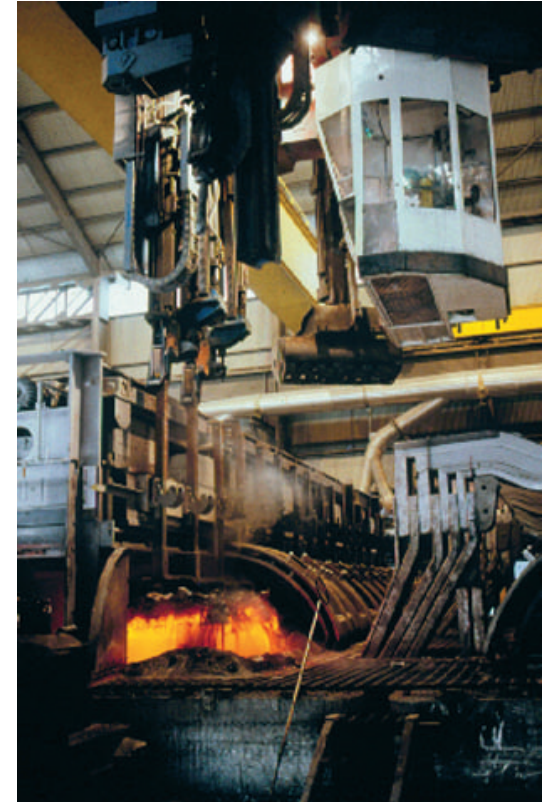

Figure 4 Overhead crane in pre-bake potroom.

exposure to static magnetic fields may be typically between 0.1 and 10.0 milliTesla with some extra low frequency (ELF) AC magnetic fields also present. Noise in potrooms can exceed $80 \mathrm{~dB}(\mathrm{~A})$ and is often loudest near the air powered (pneumatic) impact tools (electrically powered tools are often not used due to the electrical hazards in potlines) and mobile equipment. Radiant energy, as ultraviolet, visible, and infrared radiation can exceed the ACGIH TLVs ${ }^{7}$ at open pots in pre-bake smelters. Since the pots run at temperatures of about $960^{\circ} \mathrm{C}$, there is significant potential for heat stress and burns from hot electrolytic bath and metal to occur. Workers in potrooms in hot climates are particularly at risk of heat stress since the natural secondary ventilation may not afford sufficient cooling. Burns from contact with hot metal, bath splashes, or surfaces of pots are major hazards to workers in most jobs and tasks in the potroom.

Manual tasks involving lifting and incorrect posture may also be present in many of the jobs in the potroom. These hazards are present in the more common jobs such as anode changing/setting, pot tending, and tapping as well as the less routine tasks in pot maintenance.

\section{HEALTH EFFECTS}

In the early studies in the aluminium industry flurosis was considered the major health outcome, ${ }^{8}$ but with the reduction in fluoride exposures through effective fume extraction and environmental controls, this is no longer of concern in most modern potrooms. In 1984 the International Agency for 
Table 1 The hazards in potrooms

\begin{tabular}{|c|c|c|}
\hline Chemical hazards & Physical hazards & Ergonomic/psychological \\
\hline $\begin{array}{l}\text { Smelter dusts including alumina, } \\
\text { calcined coke, and refactory materials } \\
\text { (inspirable and respirable) } \\
\text { Aluminium fluorides } \\
\text { Coal tar pitch volatiles (polycyclic } \\
\text { aromatic hydrocarbons) } \\
\text { Carbon monoxide } \\
\text { Fluoride dusts } \\
\text { Hydrogen fluoride } \\
\text { Sulphur dioxide }\end{array}$ & $\begin{array}{l}\text { Electrocution } \\
\text { Electromagnetic fields } \\
\text { Falls } \\
\text { Heat } \\
\text { Mobile equipment } \\
\text { Noise } \\
\text { Vibration }\end{array}$ & $\begin{array}{l}\text { Liffing } \\
\text { Posture } \\
\text { Shift-work }\end{array}$ \\
\hline
\end{tabular}

Research on Cancer concluded: “... certain exposures in the aluminium industry are probably carcinogenic to humans". ${ }^{3}$ Working in Søderberg aluminium potrooms has been associated with increased risk of lung and bladder cancer. ${ }^{910}$ Respiratory diseases such as potroom asthma, have been the main focus of over 50 epidemiological studies since the 1960s. ${ }^{16}$ The mechanism is not clear, but may involve a mix of irritancy and sensitisation ${ }^{11}$ and asthma can continue after a worker is removed from exposure. An association between plasma fluorides and bronchial hyperresponsiveness has been shown. ${ }^{12}$ It has also been reported that workers in aluminium potrooms are at increased risk of mortality from chronic obstructive lung disease (COLD). ${ }^{\text {? }}$

\section{MEASURES TO PROTECT WORKERS}

The control of hazards in a modern potroom should involve the classical forms of workplace controls-that is, engineering controls, administrative or work practices, and personal protective equipment (PPE). With the potential for high exposure to fluorides, other gases, and particulates in potrooms, the principal control is by local exhaust ventilation (LEV). Søderberg potrooms may have a skirt hood or a complete hood over the cell. In pre-bake potrooms the local exhaust ventilation (LEV) removes the gases and particulates, to a distant location where wet or dry scrubbing takes place. Often, potrooms also have secondary emission controls such as natural ventilation to reduce the airborne contaminants and generally cool the potroom. In modern potrooms crane-drivers usually work in totally enclosed and air filtered cabins above the potlines. This greatly reduces exposure to any dusts and gases that were not captured by the primary ventilation system. Numerous mechanical lifting devices are used to work as remotely

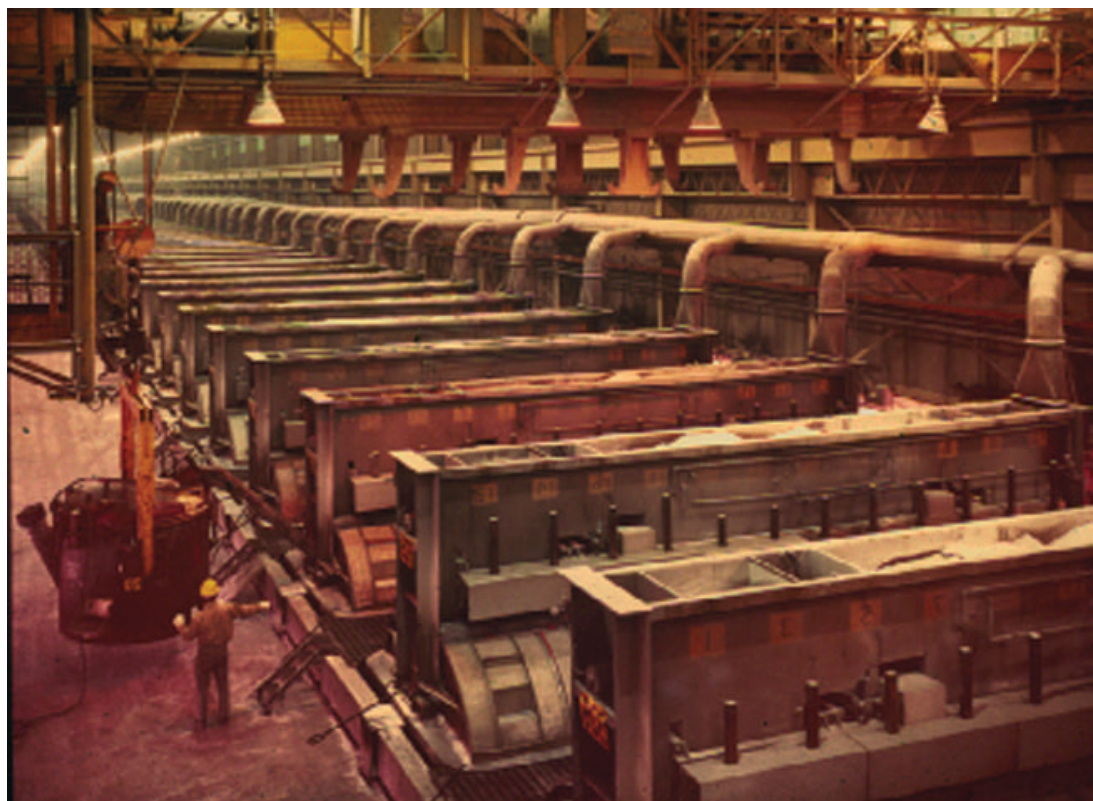

Figure 5 Fume extraction system in a pre-bake potroom. as possible from the hot metal and bath; these also reduce the likelihood of manual handling and posture injuries.

Control of hazards by work practices involve rotation of workers in various jobs and tasks and short residence times when required to work in close proximity to pots. PPE for workers in potrooms may include respiratory protection, overalls, earplugs or muffs, gloves, gaiters, safety boots, face shields, and eye protection. The respirators may be activated alumina/charcoal impregnated disposable dust masks, half-face or full-face filter respirators, or powered air purifying respirators (PAPRs), depending on the technology, tasks, and level of contaminants involved. Since the atmosphere inside potrooms is not considered immediately dangerous to life or health (IDLH), the PAPR design is popular in many potrooms. Wearing of hearing protection should be mandatory in most modern potrooms and disposable earplugs usually the most acceptable form of protection.

Medical monitoring of potroom workers can be undertaken, but this should not be seen as an alternative for hazard reduction in the workplace. The most useful aspects of such medical monitoring would include a respiratory symptom questionnaire, spirometry or peak expiratory flow rates, and measurement of airway responsiveness. ${ }^{11}$ This should also provide an opportunity for monitoring information on potroom asthma, control measures, and the correct use of PPE.

\section{ACKNOWLEDGEMENTS}

The authors wish to thank Alcoa of Australia Ltd, Portland Aluminium, and Kaal Pt Henry for their contribution of photos and the video.

Occup Environ Med 2003;60:989-992

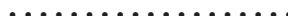

\section{Authors' affiliations}

M Sim, G Benke, Department of Epidemiology and Preventive Medicine, Monash University, The Alfred Hospital, Commercial Road, Prahran, Victoria 3181, Australia

Correspondence to: $\operatorname{Dr} M$ Sim, Department of Epidemiology and Preventive Medicine, Monash University, The Alfred Hospital Commercial Road, Prahran, Victoria 3181,

Australia; malcolm.sim@med.monash.edu.au

\section{REFERENCES}

1 Benke G, Abramson M, Sim M. Exposures in the alumina and primary aluminium industry: an historical review. Ann Occup Hyg 1998:42:173-89.

2 Burgess W. Recognition of health hazards in industry: a review of materials and processes, 2nd edn. New York: John Wiley \& Sons, 1995: 13-20.

3 International Agency for Research on Cancer (IARC). IARC monographs on the evaluation of the carcinogenic risk to humans. Vol. 34: Polynuclear aromatic compounds, Part 3, Industrial exposures in aluminium production, coal gasification, coke production and iron and steel founding. Lyon: IARC, 1984:37-64. 
4 Van Schooten F, Jongeneelen F, Hillebrand M et al. Polycyclic aromatic hydrocarbon-DNA adducts in white blood cell DNA and 1hydroxypyrene in the urine from aluminium workers: relation with job-category and synergistic effect of smoking. Cancer Epidemio Bio Prev 1995;4:69-77.

5 Rønneberg A, Landmark F. Epidemiologic evidence of cancer in aluminium reduction plant workers. Am J Ind Med 1992;22:573-90.

6 Abramson M, Wlodarczyk J, Saunders N, et al. Does aluminium smelting cause lung disease? Am Rev Respir Dis 1989;139:1042-57.
7 NIOSH. HETA 88-229-1985, Ormet Corp., Hannibal $\mathrm{OH}$, National Institute for Occupational Safety and Health, Cincinnati, $\mathrm{OH}, 1988$.

8 Agate J, Bell N, Boddie G. Industrial flurosis. Medical Research Council Memorandum No. 22. London: HMSO, 1949:19.

9 Rønneberg A. Mortality and cancer morbidity in workers from an aluminium smelter with prebaked carbon anodes - Part III: mortality from circulatory and respiratory diseases. Occup Environ Med 1995;52:255-61.

10 Tremblay C, Armstrong B, Thériault G, et al. Estimation of the risk of developing bladder cancer among workers exposed to coal tar pitch volatiles in the primary aluminium industry. Am J Ind Med 1995;27:335-48.

11 Hendrick D, Burge PS, Beckett W, Churg A, eds. Occupational disorders of the lung. London: WB Saunders, Harcourt, 2002.

12 Søyseth V, Kongerud J, Ekstrand J, et al. Relation between exposure to fluoride and bronchial responsiveness in aluminium potroom workers with work-related asthma-like symptoms. Thorax 1994:25:984-9.

13 ACGIH. Documentation of the threshold limit value and biological exposure indices, 6th edn. American Conference of Governmental industrial Hygienists. Cincinnati, OH, 1991.

\section{$\mathrm{ECHO}$}

\section{Hip pain and work or leisure activity}

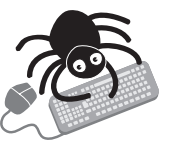

Please visit the Occupational and

Environmental Medicine website [www. occenvmed. com] for a link to the full text of this article.
$\mathrm{H}$ ip pain is commonly attributed to osteoarthritis but other causes include trochanteric bursitis and referred pain of spinal origin. There is only a weak relationship between hip pain and radiographic changes of osteoarthritis, radiographic changes being found in about a third to a half of adults with hip pain. A study based on two general practices in Cheshire has shown associations between lifetime activities during work and leisure and recent hip pain.

A total of 3847 subjects aged 18-85 years were randomly selected from the practice lists and the two practices gave a broad socioeconomic range. Postal questionnaires were sent to all subjects and 3385 completed replies were received (88\% response). Three hundred and fifty two (10.4\%) answered yes to the question "Have you experienced hip pain during the past month, lasting at least 24 hours?" and were deemed cases. The 3002 who answered "no" were controls (Hip pain status was uncertain for 31 subjects).

Occupational exposures significantly related to hip pain were: walking more than two miles a day on rough ground for at least seven years (odds ratio (OR) adjusted for age and sex, 2.65), lifting or moving weights ( $>23 \mathrm{~kg}$ ) for at least 13 years (1.9), sitting for more than two hours at a time for 1 to $18+$ years (1.9), jumping between different levels for at least 15 years (1.52), and standing for more than two hours at a time for at least 16 years (1.46).

Leisure activities significantly associated with hip pain were: track or field events with a cumulative exposure of more than 780 hours (OR 1.94), walking, cumulative duration more than 3250 hours (1.57), and running or jogging, cumulative duration more than 832 hours (1.82). On multivariate analysis three factors were independent predictors of hip pain. They were prolonged sitting at work for $1-18+$ years (OR 1.9), lifting heavy loads at work for 13 years or more (1.74), and walking during leisure time for a cumulative duration at least 3250 hours (1.97). The population attributable risk associated with each of these activities was $21 \%, 13 \%$, and $16 \%$ respectively.

The prevalence of hip pain in this study was similar to rates reported from previous population based studies. Associations between occupational heavy lifting and hip osteoarthritis have been reported previously but associations with recreational walking or prolonged sitting at work have not been reported before. One study found that a history of prolonged sitting at work was less common among cases awaiting hip arthroplasty. These three factors are common and their combined population attributable risk was put at $50 \%$.

A Annals of the Rheumatic Diseases 2003;62:322-326. 